\title{
Analogies de profils plasmidiques chez les streptocoques du groupe $\mathbf{N}$
}

\author{
par \\ A. CHOPIN* et P. LANGELLA
}

\section{Ré s u m é}

Les plasmides de 60 souches de streptocoques du groupe $\mathrm{N}$ ont été extraits selon la méthode de Gasson et Davies (1980), et visualisés après électrophorèse en gel d'agarose. La méthode de Hintermann et al. (1981), qui permet de distinguer les bandes d'acide désoxyribonucléique sous forme surenroulée de celles sous forme relâchée, nous a permis d'établir que dans les conditions d'extraction utilisées, les plasmides étaient régulièrement trouvés sous les deux formes et qu'une seule électrophorèse en gel d'agarose conduisait à surestimer le nombre de plasmides. Les plasmides de poids moléculaire supérieur à 30-45 Mdaltons n'ont pas été mis en évidence convenablement par cette méthode.

Nous avons trouvé des plasmides dans toutes les souches étudiées. Sept souches présentaient des analogies de leurs profils plasmidiques. Il s'agissait soit de souches provenant d'un ancêtre commun, soit de souches présentant une sensibilité identique à 132 bactériophages. L'étude des profils plasmidiques semble donc constituer un moyen simple pour reconnaître les souches de streptocoques du groupe N. Parmi les 11 souches de Streptococcus lactis subsp. diacetylactis étudiées, 10 possédaient un plasmide de 5,4 Mdaltons probablement identique au plasmide de 5,5 Mdaltons qui code pour la production d'une citrate perméase.

Titre abrégé

Plasmides de streptocoques du groupe N.

Mots clés

Plasmide - Streptococcus lactis - Streptococcus lactis subsp. diacetylactis Streptococcus cremoris - Electrophorèse - Acide Désoxyribonucléique - ADN Lysotype.

* Institut National de la Recherche Agronomique, Laboratoire de Rercherches de Technologie Laitière, 65, rue de Saint-Brieuc - 35042 Rennes cedex (France). 


\section{S u m m a r y}

\section{PLASMID PROFILES ANALOGIES IN GROUP N STREPTOCOCCI}

Plasmid DNA from 60 group $N$ Streptococci strains was extracted using the method described by Gasson and Davies (1980). The extracts were subjected to a two-dimensional agarose gel electrophoresis according to Hintermann et al. (1981), which enables to distinguish plasmid DNA bands under a covalently closed circular (CCC) form from those under an open circular (OC) form. Plasmid DNA was often found to be present in the extracts under the two molecular forms, giving an overestimated number of plasmid species after a simple electrophoresis. Plasmids larger than 30-45 Mdaltons could not be consistently extracted using this method. Plasmids were found in all the tested strains and seven strains were found to show analogies in their plasmid profiles. These strains showing analogies in their plasmid profiles were (i) strains obtained from different micro-organisms collections but deriving from the same original strain (ii) strains showing an identical sensitivity pattern to 132 bacteriophages. Plasmid profile determinations may offer an easy way to recognize group $N$ streptococci strains. Among 11 Streptococcus lactis subsp. diacetylactis strains tested, 10 possessed a 5.4 Mdaltons plasmid which is probably equivalent to the 5.5 Mdaltons citrate permease plasmid.

Key words

Plasmid - Streptococcus lactis - Streptococcus lactis subsp. diacetylactis Streptococcus cremoris - Electrophoresis - Deoxyribonucleic Acid - DNA Lysotype.

\section{INTRODUCTION}

Depuis la première mise en évidence de plasmides chez les streptocoques du groupe N (Efstathiou et Mc Kay, 1976), l'étude des plasmides de ces bactéries a connu un développement rapide (Davies et Gasson, 1981). En particulier, la mise au point de méthodes rapides d'extraction (Klaenhammer et al., 1978; Gasson et Davies, 1980 a) a permis d'étudier les profils plasmidiques de nombreuses souches (Pechmann et Teuber, 1980; Davies et al., 1981). Ces travaux ont montré que toutes les souches étudiées donnaient des bandes d'ADN plasmidique et pour certaines en nombre exceptionnellement élevé (jusqu'à 14) (Davies et al., 1981). Il se peut néanmoins que ceci ne représente pas 14 plasmides différents, puisque l'on sait que, selon la technique d'extraction utilisée, un même plasmide peut avoir son acide désoxyribonucléique (ADN) présent dans l'extrait sous différentes formes (surenroulée, relâchée et linéaire), donnant des bandes distinctes en électrophorèse (Willshaw et al., 1979). 
Ces travaux ont également révélé des analogies dans l'équipement plasmidique de certaines souches. Pechmann et Teuber (1980), étudiant 51 souches, en ont trouvé le tiers qui présentaient des profils plasmidiques analogues. Cette fréquence des analogies n'a pas été confirmée par Davies et al. (1981), qui étudiant un grand nombre de souches ont trouvé des profils plasmidiques variés, spécifiques des souches et seulement quatre souches qui présentaient des profils plasmidiques analogues. Ces auteurs ont établi que, bien que provenant de différentes collections de micro-organismes, ces 4 souches dérivaient en fait de la même souche d'origine ce qui les a amenés à envisager l'utilisation des profils plasmidiques pour reconnaître les souches.

Disposant d'une importante collection de souches de streptocoques du groupe $\mathrm{N}$, d'origine variée et classées en fonction de leur sensibilité à 132 bactériophages (Chopin et al. 1976), nous avons voulu déterminer les profils plasmidiques de certaines d'entr'elles et chercher à savoir si les ressemblances plus ou moins marquées, présentées par ces souches dans leur sensibilité aux phages, étaient également observées au niveau de leur profils plasmidiques.

Pour cela, nous avons utilisé la technique d'extraction plasmidique décrite par Gasson et Davies (1980 a), légèrement modifiée. La méthode d'électrophorèse bidimensionnelle de Hintermann et al. (1981) nous a permis de distinguer les formes surenroulées d'ADN des formes relâchées ou linéaires présentes dans les extraits. Une grande variété de plasmides a été observée et des analogies n'ont été trouvées qu'entre souches apparentées.

\section{MATERIEL ET METHODES}

\section{Souches de micro-organismes}

Les 60 souches de streptocoques du groupe sérologique $\mathrm{N}$ utilisées dans cette étude ont été choisies dans une collection de 291 souches préalablement classées en fonction de leurs sensibilités à 132 bactériophages (Chopin et al. 1976). Les souches utilisées ont été choisies de façon à donner une image représentative de cette vaste collection, à la fois pour la répartition en espèces et pour les caractères de sensibilité ou de résistance aux phages des différents groupes préalablement définis. Nous avons inclus dans notre étude des souches présentant des sensibilités aux phages identiques afin de comparer leurs équipements plasmidiques.

La répartition en espèces était la suivante: Streptococcus lactis : 33 souches, Streptococcus cremoris : 16 souches et Streptococcus lactis subsp. diacetylactis : 11 souches. Neuf de ces souches provenaient de collections étrangères. Il s'agit des souches $\mathrm{C} 2, \mathrm{C} 10$, 
R1 et HP fournies par J. Czulak (Australie), de la souche ML8 fournie par L.E. Pearce (Nouvelle-Zélande), des souches 607 et 700 de la National Collection of Dairy Organism (Shinfield, Grande-Bretagne), de la souche 19 fournie par W. Sandine (U.S.A.) et d'une souche de la collection du Olsztyn Laboratory of Pure Dairy Cultures (Pologne). Les 51 autres souches étudiées provenaient pour 11 d'entr'elles de la collection du Centre National de Recherches Zootechniques (CNRZ, Jouy-en-Josas, France) et pour les 40 autres de la collection de l'Institut National Agronomique (Paris, France). Toutes ces 51 souches avaient été isolées à partir de produits laitiers en France ou en Belgique de 1954 à 1971.

Vingt-cinq souches provenaient de levains de fromagerie commerciaux, 5 de lait cru, 1 de crème crue et 3 de fromages (Brie, Tome de Savoie, Saint Nectaire), 13 souches provenaient de produits laitiers non précisés. Les souches avaient été conservées soit congelées à $-40^{\circ} \mathrm{C}$ dans du lait, soit lyophilisées dans du lait.

Des souches de référence ont également été utilisées dans cette étude. Streptococcus faecalis DS5 reçue de T. Horaud (Institut Pasteur, Paris) contient les plasmides $\mathrm{pAM} \alpha 1, \mathrm{pAM} \beta 1, \mathrm{pAM} \gamma 1$ de poids moléculaires respectifs 6,$0 ; 17$ et 35 Mdal. Streptococcus lactis SH4174, reçue de M. Gasson (Shinfield, Grande-Bretagne), dérivée de Streptococcus lactis NCDO 712 (Gasson et Davies, 1980 b) contient, outre le plasmide pAM $\beta 1$, des plasmides de poids moléculaires respectifs 5,2 ; 2,5 et 1,8 Mdal (Davies et al., 1981). Enfin, 3 souches de Streptococcus faecalis reçues de P. Courvalin (Institut Pasteur, Paris) contenant des plasmides de grande taille : pIP614 de $65 \mathrm{Mdal}$, pJH5 de 76 Mdal et pIP800 de 70 Mdal.

\section{Extraction des plasmides}

Nous avons utilisé la méthode d'extraction développée par Gasson et Davies (1980 a), légèrement modifiée comme suit : $30 \mathrm{ml}$ de culture de $4 \mathrm{~h}$ à $30^{\circ} \mathrm{C}$ sur bouillon M17 (Terzaghi et Sandine, 1975) étaient centrifugés dans un tube en polyéthylène pendant $10 \mathrm{~min}$ à $3000 \mathrm{~g}$ et le culot était remis en suspension dans $30 \mathrm{ml}$ d'eau distillée à $4^{\circ} \mathrm{C}$. Les cellules étaient centrifugées à nouveau pendant $10 \mathrm{~min}$ à $3500 \mathrm{~g}$ et le culot était remis en suspension dans $26 \mathrm{ml}$ d'une solution de saccharose à $25 \%(\mathrm{p} / \mathrm{v})$ à $4 \% \mathrm{C}$. On ajoutait $4 \mathrm{ml}$ d'une solution de lysozyme à $10 \mathrm{mg} / \mathrm{ml}$ préparée extemporanément et le tube était laissé en attente pendant 5 min dans la glace fondante ce qui amenait les cellules à l'état de protoplastes. Les protoplastes étaient centrifugés à $1500 \mathrm{~g}$ pendant $30 \mathrm{~min}$ à $4^{\circ} \mathrm{C}$ et remis en suspension avec précaution dans $1 \mathrm{ml}$ de solution de saccharose à $25 \%(\mathrm{p} / \mathrm{v})$ à température ambiante. On ajoutait $50 \mu \mathrm{l}$ de diéthylpyrocarbonate pour inhiber les nucléases éventuellement présentes et $1 \mathrm{ml}$ d'une solution contenant : dodécylsulfate de sodium (DSS) 
$1 \%(\mathrm{p} / \mathrm{v})$, tris $100 \mathrm{mM}, \mathrm{Na}_{2}$ EDTA $50 \mathrm{mM}, \mathrm{NaCl} 800 \mathrm{mM}(\mathrm{pH} 8,0)$ pour lyser les protoplastes. Le tube était agité doucement et laissé $10 \mathrm{~min}$ à température ambiante. Il était ensuite refroidi dans la glace et on ajoutait $0,5 \mathrm{ml}$ d'une solution de $\mathrm{NaCl} 5 \mathrm{M}$. Le tube était gardé au moins $30 \mathrm{~min}$ dans la glace pour permettre la précipitation du complexe DSS-ADN chromosomique-protéines et le lysat clair était obtenu par centrifugation à $30000 \mathrm{~g}$ pendant $30 \mathrm{~min}$ à $4^{\circ} \mathrm{C}$.

Le lysat clair surnageant contenant l'ADN plasmidique était transféré dans un tube en nitrate de cellulose et déprotéinisé par addition de $2,5 \mathrm{ml}$ d'un mélange chloroforme : alcool iso-amylique (24:1) et mélangé par inversions douces. Le tube était refroidi dans la glace et centrifugé à $14000 \mathrm{~g}$ pendant $20 \mathrm{~min}$ à $4^{\circ} \mathrm{C}$. Deux $\mathrm{ml}$ du surnageant étaient prélevés avec précaution, en évitant d'entraîner le précipité présent à l'interface, et transférés dans un nouveau tube en polyéthylène. L'ADN plasmidique était précipité par addition de 0,5 ml d'acétate de sodium $3 \mathrm{M}$ et de $6 \mathrm{ml}$ d'éthanol absolu. Après $30 \mathrm{~min}$ d'attente à température ambiante, le tube était centrifugé à $14000 \mathrm{~g}$ pendant $20 \mathrm{~min}$. Le surnageant était vidé et soigneusement égoutté. Le précipité d'ADN plasmidique était redissout dans $300 \mu \mathrm{l}$ de tampon TE-RNase (Tris $10 \mathrm{mM}$, Na ${ }_{3}$ EDTA $1 \mathrm{mM}$, RNase A $10 \mu \mathrm{g} / \mathrm{ml}$, $\mathrm{pH} 7,5)$. L'extrait plasmidique pouvait être ensuite conservé plusieurs semaines à $4^{\circ} \mathrm{C}$.

Nous avons aussi utilisé cette même méthode en supprimant l'étape de déprotéinisation du lysat clair par le mélange chloroforme : alcool iso-amylique. Dans ce cas, le lysat clair était directement additionné d'acétate de sodium et d'éthanol pour précipiter l'ADN plasmidique.

\section{Electrophorèse des extraits plasmidiques en gel d'agarose}

La composition en plasmides des extraits était déterminée soit par électrophorèse verticale en gel d'agarose (Sigma Type V) selon Meyers et al. (1976), soit par électrophorèse horizontale en gel d'agarose en tampon tris $40 \mathrm{mM}$, acétate de $\mathrm{Na} 20 \mathrm{mM}$, Na $\mathrm{NaDTA}_{2} 2 \mathrm{mM}$ ajusté à $\mathrm{pH} 8,3$ par addition d'acide acétique glacial. Chaque extrait était examiné sur deux gels, l'un contenant $0,7 \%$, l'autre contenant $1 \%$ d'agarose. L'utilisation de deux concentrations d'agarose différentes avait pour but la détection de certaines bandes d'ADN qui pouvaient être masquées par la bande d'ADN chromosomique sur l'un ou l'autre des gels. Après électrophorèse pendant $16 \mathrm{~h}$ à $2,5 \mathrm{~V} \cdot \mathrm{cm}^{-1}$, les gels étaient colorés pendant $30 \mathrm{~min}$ dans une solution de bromure d'éthidium à $0,5 \mu \mathrm{g} / \mathrm{ml}$ et examinés en lumière ultraviolette $(300 \mathrm{~nm})$ en utilisant un transilluminateur U-V Products, modèle C-63. Les gels étaient photographiés à l'aide d'un appareil Polaroïd MP-3, muni d'un filtre orange et d'un filtre UV, chargé avec un film Polaroïd 667. 


\section{Distinction des formes surenroulées, relâchées et linéaires d'ADN plasmidique}

Willshaw et al. (1979) ont établi que les bandes d'ADN plasmidique visualisées par électrophorèse pouvaient correspondre à un même ADN plasmidique sous différentes formes (surenroulée, relâchée ou linéaire). C'est pourd zoi nous avons distingué ces formes par électrophorèse bidimensionnelle en utilisant la méthode de Hintermann et al. (1981) : après électrophorèse, coloration et photographie du gel, la piste contenant les différentes bandes d'ADN plasmidique à distinguer était découpée et irradiée pendant 4 min sous une lampe à ultra-violets $(254 \mathrm{~nm})$ avec une intensité d'environ 500 erg. $\mathrm{mm}^{-2}$. Cette irradiation des bandes d'ADN plasmidique en présence de bromure d'éthidium engendre des ruptures dans les molécules d'ADN qui transforment une partie des formes surenroulées en formes relâchées. La piste irradiée était ensuite incluse dans un nouveau gel à $0,7 \%$ d'agarose et soumise à une nouvelle électrophorèse dans une direction perpendiculaire. Après coloration et photographie, le diagramme obtenu était interprété comme suit (fig. 1) : les formes relâchées d'une espèce plasmidique donnée, formées au cours de l'irradiation UV, migraient à la même distance que les formes relâchées de cette même espèce plasmidique originellement présentes dans l'extrait. La forme relâchée originellement présente, la forme relâchée induite au cours de l'irradiation et la forme surenroulée correspondante étaient donc placées aux sommets d'un triangle rectangle après électrophorèse dans la seconde dimension.

\section{Estimation des poids moléculaires des plasmides}

Les poids moléculaires des plasmides ont été estimés par le calcul en utilisant l'observation de Meyers et al. (1976) selon laquelle le logarithme de la migration relative d'une bande de plasmide, sous forme surenroulée, est fonction linéaire du logarithme de son poids moléculaire. On incluait dans chaque gel un extrait plasmidique de Streptococcus faecalis DS5 et de Streptococcus lactis SH4174 contenant des plasmides de poids moléculaires connus pour servir de référence.

\section{RESULTATS}

\section{Distinction des formes surenroulées, relâchées et linéaires d'ADN plasmidique}

La méthode de Hintermann et al. (1981) nous a permis, à partir de profils électrophorétiques souvent très complexes, pouvant montrer jusqu'à 20 bandes différentes, de distinguer les différentes formes d'ADN et de repérer les bandes correspondant à de l'ADN 


Electrophorèse de l'extrait Electrophorèse bidimensionnelle $\begin{array}{r}\text { Interprétation } \\ \text { plasmidique de } \mathrm{AO} 83\end{array}$
des bandes a)

\section{Electrophoresis of $\mathrm{A} 083$ plasmid extract}
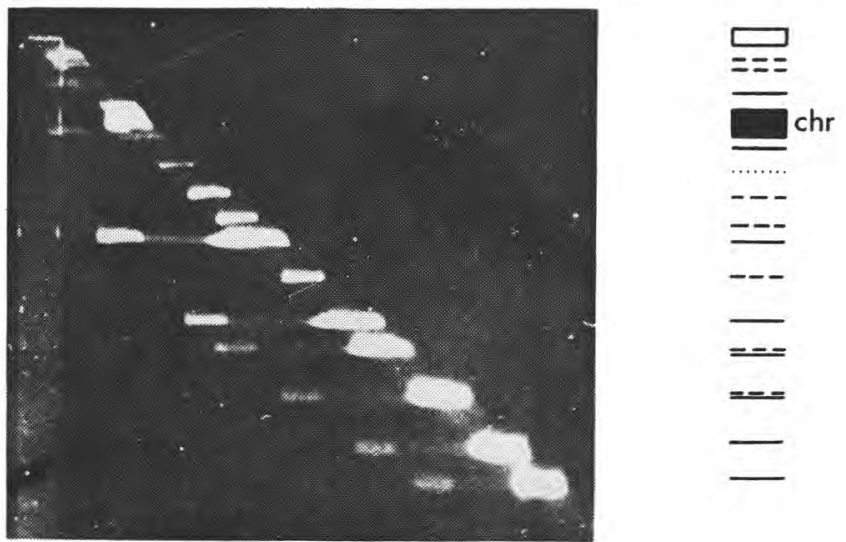

Fig. 1

Utilisation de l'électrophorèse bidimensionnelle pour la distinction des formes surenroulées, relâchées et linéaires de l'ADN plasmidique de Streptococcus lactis subsp. diacetylactis A083

Use of two-dimensional electrophoresis for distinguishing CCC, OC and L forms Streptococcus lactis subsp. diacetylactis A083

a) — : plasmid sous forme surenroulée, CCC form of plasmid DNA.

- - — : plasmide sous forme relâchée, OC form of plasmid DNA.

....... : plasmide sous forme linéaire, $\mathrm{L}$ form of plasmid DNA.

chr : chromosome.

Après électrophorèse de l'ADN plasmidique de la souche A083, on obtient un profil montrant au moins 14 bandes. Après découpe et irradiation de la piste d'agarose aux UV, on procède à une électrophorèse dans une seconde direction perpendiculaire à la première comme indiqué dans le texte. Les molécules d'ADN sous forme surenroulée donnent naissance à des formes relâchées qui migrent au même niveau que les formes relâchées présentes dans l'extrait de départ.

After electrophoresis of plasmid DNA extract from strain A083, a slot showing at least 14 bands is obtained. The slot is then cut off, irradiated with UV light and run in a second perpendicular direction as described in the text. The CCC forms of DNA partially relaxes into OC forms which have the same mobility as the OC DNAs originally present in the plasmid preparation. 


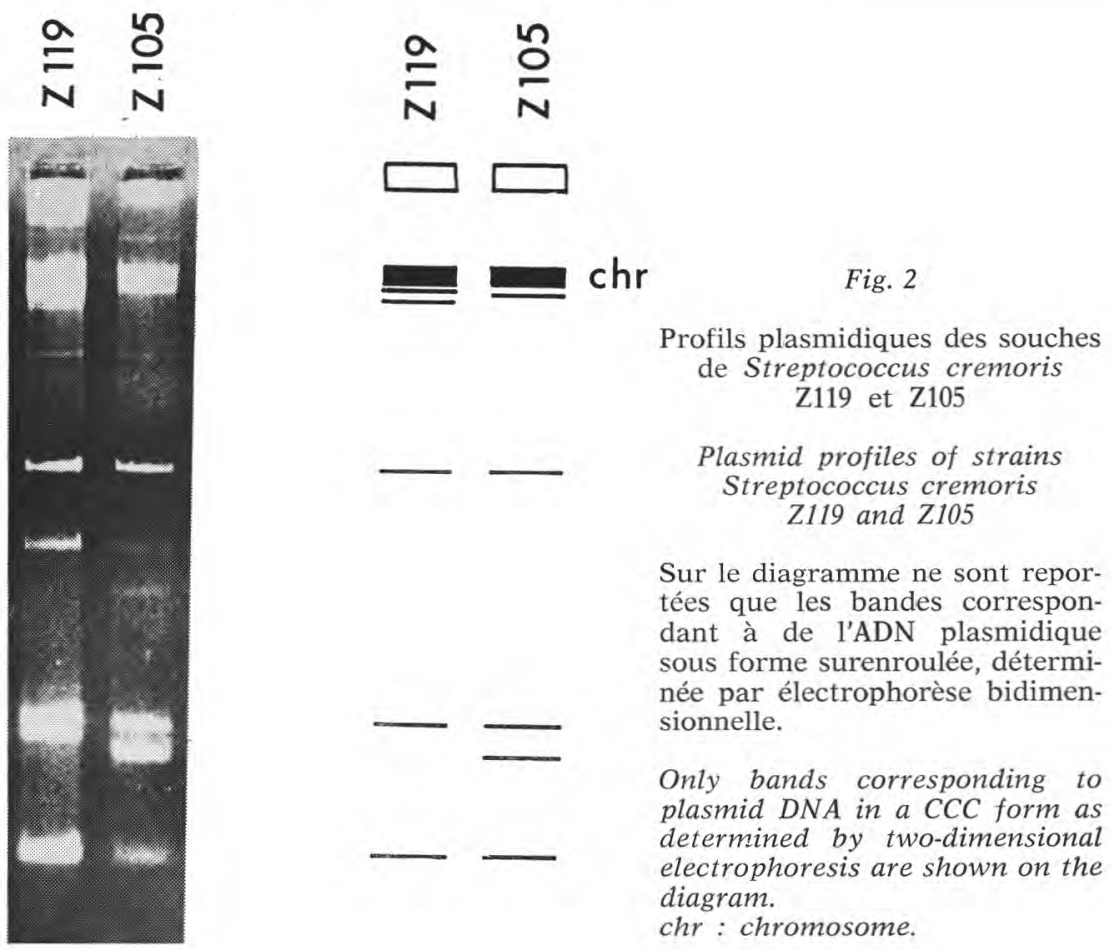

plasmidique sous forme surenroulée. La figure 1 donne l'exemple de la souche de Streptococcus lactis subsp. diacetylactis A 83 dont l'extrait plasmidique révèle plus de 14 bandes et dont l'électrophorèse bidimensionnelle montre qu'elle contient en fait 8 plasmides différents.

Avec toutes les souches étudiées, nous avons obtenu des extraits plasmidiques contenant de l'ADN sous les deux formes surenroulée et relâchée. La forme relâchée d'un plasmide donné, généralement moins abondante que sa forme surenroulée, donnait des bandes moins lumineuses. Occasionnellement, certaines bandes très peu lumineuses ne pouvaient être considérées ni comme des formes surenroulées ni comme des formes relâchées. Nous avons admis qu'il s'agissait d'ADN d'origine plasmidique ou chromosomique sous forme linéaire.

Nous n'avons pas réussi à diminuer l'importance des formes ouvertes d'ADN plasmidique dans les extraits en diminuant les contraintes mécaniques exercées sur l'ADN au cours de l'extraction 


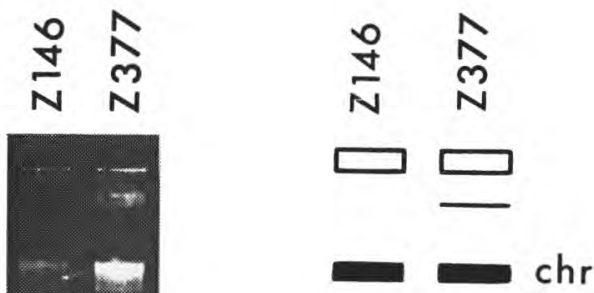

Fig 3

Profils plasmidiques des souches de Streptococcus lactis Z146 et Z377

Plasmid profiles of strains Streptococcus lactis Z146 and Z377

Sur le diagramme ne sont reportées que les bandes correspondant à de l'ADN plasmidique sous forme surenroulée, déterminées par électrophorèse bidimensionnelle.

Only bands corresponding to plasmid DNA in a CCC form as determined by two-dimensional electrophoresis are shown on the diagram. chr : chromosome.

(suppression de l'étape de déprotéinisation et des agitations, pipettages réalisés avec des pipettes à gros bouts).

\section{Equipement plasmidique des streptocoques du groupe $\mathrm{N}$}

Des bandes d'ADN plasmidique ont été observées dans une échelle de poids allant de 2 à plus de 30 Mdaltons. La luminosité des plasmides de petite taille ( $\mathrm{du}$ fait de leur plus grand nombre de copies) était supérieure à celle des plasmides de plus grande taille (30 Mdaltons et au-dessus). Ces derniers étaient en outre souvent masqués par des bandes diffuses correspondant aux formes relâchées des plasmides plus petits. Même en ayant recours à l'électrophorèse bidimensionnelle, il n'était pas toujours possible de conclure quant à la présence ou à l'absence de plasmides de grande taille.

Pour préciser la limite de la technique d'extraction utilisée, nous l'avons appliquée à des souches de Streptococcus faecalis contenant des plasmides parmi les plus gros trouvés chez les streptocoques 


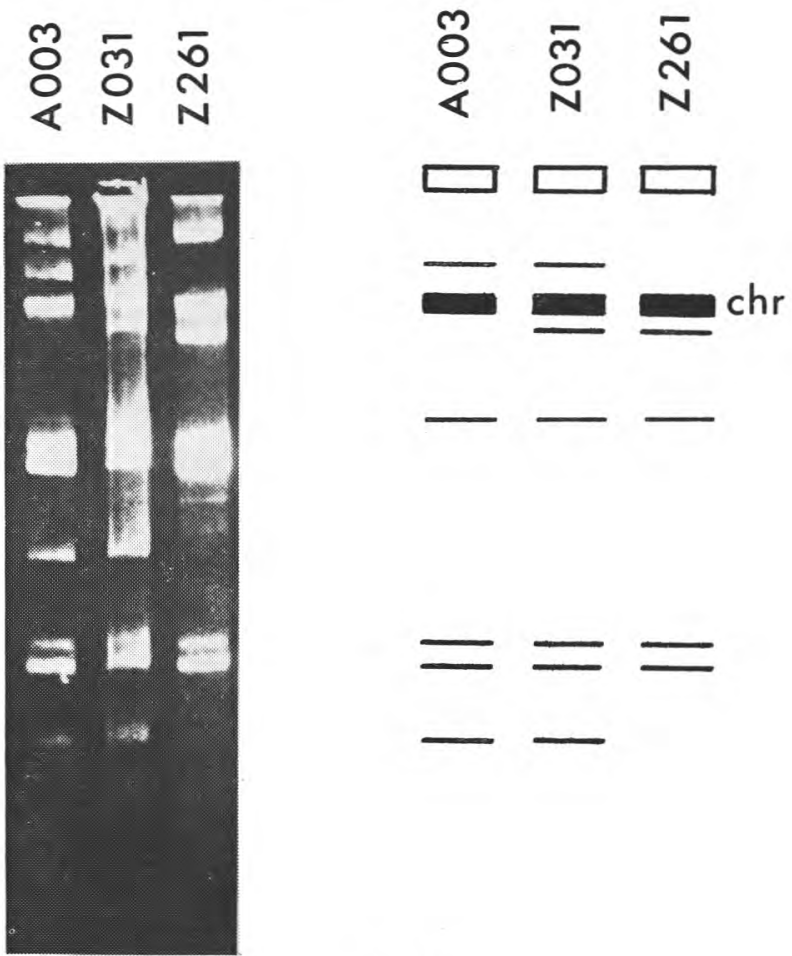

Fig. 4

Profils plasmidiques des souches de Streptococcus lactis A003, Z031 et Z261.

Plasmid profiles of strains Streptococcus lactis A003, Z031 and Z261.

Sur le diagramme ne sont reportées que les bandes correspondant à de l'ADN plasmidique sous forme surenroulée, déterminées par électrophorèse bidimensionnelle.

Only bands corresponding to plasmid DNA in a CCC form as determined by two-dimensional electrophoresis are shown on the diagram.

chr : chromosome.

(pIP614 de 65 Mdal, pJH5 de 76 Mdal et pIP800 de 70 Mdal) (Clewell, 1981). Nous n'avons pas réussi à extraire ces plasmides de façon satisfaisante.

Néanmoins, cette méthode d'extraction de plasmides nous a permis de trouver des plasmides dans les 62 souches étudiées. Leur nombre allait de 1 à plus de 9 . Les profils plasmidiques trouvés 

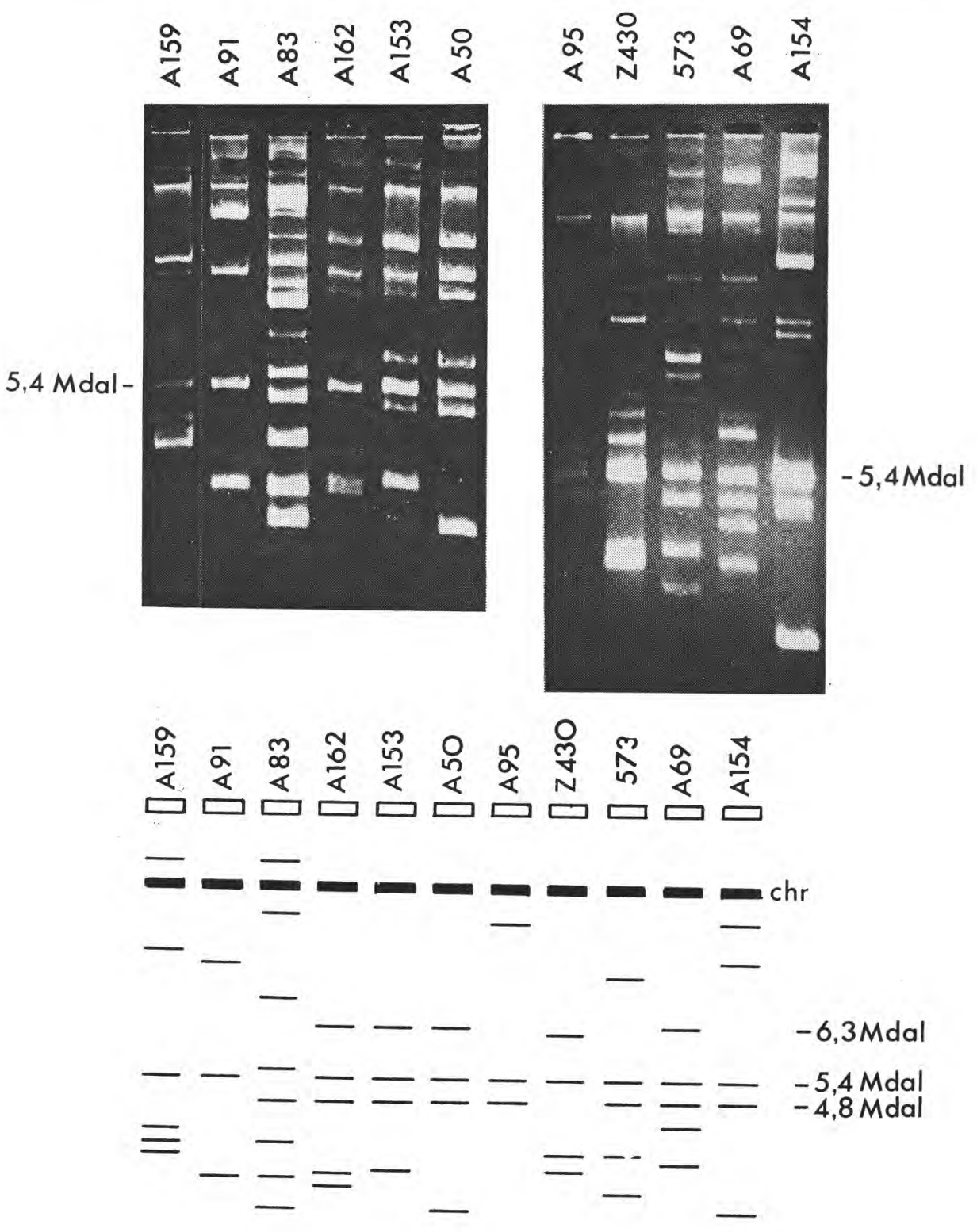

Fig. 5

Profils plasmidiques des souches de Streptococcus lactis subsp. diacetylactis

Plasmid profiles of strains of Streptococcus lactis subsp. diacetylactis

Sur le diagramme ne sont reportées que les bandes correspondant à de l'ADN plasmidique sous forme surenroulée, déterminées par électrophorèse bidimensionnelle.

Only bands corresponding to plasmid DNA in a CCC form as determined by twodimensional electrophoresis are shown on the diagram.

chr: chromosome. 
étaient assez diversifiés puisque parmi les 62 souches étudiées, 42 possédaient un profil plasmidique distinct de celui des autres souches. Les profils plasmidiques des 18 autres souches sont présentés dans les figures 2 à 5 . On constate que deux paires de souches ont des profils plasmidiques analogues. II s'agit des souches Z119 et Z105, Z146 et Z377. En recherchant les origines de ces souches, nous avons pu établir qu'il s'agissait de souches portant des références différentes mais dérivant en fait d'une même souche parentale. Z119 a été reçue de J. Czulak en 1958 sous la désignation Str. cremoris HP alors que Z105 provient de la souche NCDO 607 qui a été reçue de H.R. Whitehead en 1937 sous la même désignation de Str. cremoris HP. Z146 a été reçue de J. Czulak en 1958 sous la désignation Str. lactis $\mathrm{C} 10$ alors que Z377 a été reçue de E. Pearce en 1971 sous la désignation Str. lactis ML8. Les archives de la collection du CNRZ nous ont permis de confirmer que les souches C10 (désignation de CSIRO australien) et ML8 (désignation du NZRI néo-zélandais) avaient en fait la même origine (souche isolée par United Dairies UK).

Un autre groupe rassemble 3 souches aux profils plasmidiques analogues (fig. 4). A003 est une souche de Streptococcus lactis isolée en France en 1962 par R. Chevalier de lait frais en provenance du Jura. Z31 et Z261 ont été isolées vers 1960 par R. Mourgues dans une ferme où était fabriqué du fromage de Brie (Z261 a été isolée de lait frais et Z31 de lactosérum).

Enfin, parmi les 11 souches de Streptococcus lactis subsp. diacetylactis étudiées (fig. 5), 10 possèdent un plasmide d'un poids estimé à 5,4 Mdal, 8 un plasmide d'un poids estimé à 4,8 Mdal et 4 un plasmide d'un poids estimé à $6,3 \mathrm{Mdal}$.

\section{DISCUSSION}

Les résultats obtenus montrent que la méthode que nous avons utilisée pour extraire les plasmides présents dans les streptocoques du groupe $\mathrm{N}$ présente certaines limites :

- elle ne nous a pas permis de mettre en évidence de façon satisfaisante les plasmides de poids moléculaire supérieur à 30-45 Mdaltons. Cela est dû à la faible luminosité des bandes correspondant aux gros plasmides, due elle-même à un petit nombre de copies (Clewell, 1981) et au fait que ces bandes sont souvent masquées par des bandes plus lumineuses d'ADN sous forme ouverte;

- elle aboutit à un extrait plasmidique dans lequel une fraction relativement importante de l'ADN est sous forme relâchée. L'électrophorèse de ces extraits conduit à un nombre de bandes bien supérieur au nombre de plasmides présents dans la souche étudiée 
dont il serait nécessaire de confirmer le profil plasmidique par une électrophorèse bidimensionnelle.

Quelques essais préliminaires, réalisés en utilisant une méthode d'extraction des plasmides comportant une étape de dénaturation alcaline (Hansen et Olsen, 1978), ont permis d'obtenir un meilleur rendement d'extraction des gros plasmides tout en produisant moins d'ADN sous forme ouverte. Cette méthode, déjà utilisée par Walsh et Mc Kay (1981) pour mettre en évidence un plasmide de 60 Mdaltons chez Streptococcus lactis pourrait donc constituer une méthode mieux adaptée que la méthode de Gasson et Davies (1980 a) pour l'extraction des gros plasmides de streptocoques du groupe N.

Néanmoins, malgré ses limites, la méthode utilisée nous a permis d'établir des comparaisons entre les profils plasmidiques des souches étudiées. Au total, parmi 60 souches, nous n'en avons trouvé que 7 dont le profil plasmidique était analogue à celui d'une autre souche. Cela est nettement différent des résultats de Pechmann et Teuber (1980) qui, à partir de 51 souches étudiées, en ont trouvé $33 \%$ présentant des profils plasmidiques analogues. Cette différence semble provenir de la variété des souches que nous avons étudiées quant à leur origine. Pour ce qui concerne les souches présentant des profils plasmidiques analogues, nous avons observé que (i) elles provenaient d'un ancêtre commun (cas des souches Z119 et Z105, Z146 et Z377) ou que (ii) elles présentaient des spectres de sensibilité identiques à 132 bactériophages (cas des souches A003, Z031 et Z261) (M.C. Chopin, communication personnelle).

Dans le premier cas, l'analogie des profils plasmidiques n'est pas surprenante et l'on peut supposer que les légères différences observées dans ces profils résultent de variations dans les pressions de sélection exercées sur ces souches au cours de leur conversation dans les diverses collections. Dans le second cas, on a affaire à 3 souches vraisemblablement très proches et il se pose la question d'une origine commune de ces 3 souches. Si les souches Z031 et Z261 ont très probablement la même provenance (isolées au même moment dans la même ferme), la souche A003 (isolée 2 ans plus tard d'un lait frais en provenance d'une autre région de France) a certainement été soumise à une longue période d'évolution dans un environnement différent. Dans ces conditions, il est inhabituel que le profil plasmidique soit resté stable d'autant que l'on sait que les streptocoques du groupe $\mathrm{N}$ peuvent perdre spontanément certains de leurs plasmides (Efstathiou et Mc Kay, 1976) ou en acquérir de nouveaux par conjugaison (Kempler et Mc Kay, 1979 b). Il faut donc admettre pour expliquer cette stabilité que les plasmides présents dans cette souche lui confèrent un net avantage écologique dans un environnement laitier. La spécificité des profils plasmidiques des souches que nous avons étudiées ainsi que leur stabilité, confirment l'intérêt des comparaisons de profils plasmidiques pour 
distinguer ou reconnaître les souches de streptocoques du groupe $\mathrm{N}$ comme cela a été suggéré par Davies et al. (1981).

Nous avons également mis en évidence que le groupe des Streptococcus lactis subsp. diacetylactis rassemble des souches qui ont un ou quelques plasmides de même poids moléculaire en commun. Cependant, il est difficile, au vu de ces seuls résultats de se prononcer quant à l'homologie de ces plasmides. Mais il est très probable que le plasmide de 5,4 Mdaltons mis en évidence dans 10 des 11 souches de Streptococcus lactis subsp. diacetylactis que nous avons étudiées, soit identique au plasmide de 5,5 Mdaltons que Kempler et Mc Kay $(1979$ a, 1981) ont trouvé dans les 5 souches de Streptococcus lactis subsp. diacetylactis qu'ils ont étudiées, et dont ils ont montré qu'il codait pour la production d'une citrate perméase par ces souches.

Reçu pour publication en août 1982.

\section{Remerciements}

Nous remercions Agnès Batt et Marie-Christine Chopin pour leur aide dans la réalisation du travail et la préparation du manuscrit.

\section{Bibliographie}

Chopin (M. C.), Chopin (A.) and Roux (C.) (1976). - Definition of Bacteriophage Groups According to Their Lytic Action on Mesophilic Lactic Streptococci. Appl. Environ. Microbiol., 32 (6) 741-746.

Clewell (D. B.) (1981). - Plasmids, Drug Resistance, and Gene Transfer in the Genus Streptococcus. Microbiol. Reviews, 45 (3), 409-436.

Davies (F. L.), Underwood (H. M.) and Gasson (M. J.) (1981). - The Value of Plasmid Profiles for Strain Identification in Lactic Streptococci and the Relationship between Streptococcus lactis 712, ML3 and C2. J. Appl. Bacteriol., 51, 325-337.

Davies (F. L.) and Gasson (M. J.) (1981). - Reviews of the progress of Dairy Science: Genetics of lactic acid bacteria. J. Dairy Res., 48, 363-376.

Efstathiou (J. D.) and Mc Kay (L. L.) (1976). - Plasmids in Streptococcus lactis: evidence that lactose metabolism and proteinase activity are plasmid linked. Appl. Environ. Microbiol., 32, 38-44.

Elliker (P. R.), ANDerson (A. W.) and Hannesson (G.) (1956). - An agar culture medium for lactic acid streptococci and lactobacilli. J. Dairy Sci., 39, 1611-1612.

Gasson (M. J.) and Davies (F. L.) (1980 a). - High-frequency conjugation associated with Streptococcus lactis donor cell aggregation. J. Bacteriol., 143, $1260-1264$.

Gasson (M. J.) and Davies (F. L.) (1980 b). - Conjugal Transfer of the Drug Resistance Plasmid pAM $\beta$ in the Lactic Streptococci. FEMS Microbiol. Letters, 7, 51-53.

Hansen (J. B.) and Olsen (R. H.) (1978). - Isolation of Large Bacterial Plasmids and Characterization of the P2 Incompatibility Group Plasmids pMG1 and pMG5. J. Bacteriol., 135, 227-238. 
Hintermann (G.), Fischer (H. M.), Crameri (R.) and Hutter (R.) (1981). Simple procedure for distinguishing $\mathrm{CCC}$, OC and $\mathrm{L}$ forms of Plasmid DNA by Agarose Gel Electrophoresis. Plasmid, 5, 371-373.

Kempler (G. M.) and Mc KaY (L. L.) (1979 a). - Characterization of plasmid deoxyribonucleic acid in Streptococcus lactis subsp. diacetylactis: evidence for plasmid-linked citrate utilisation. Appl. Environ. Microbiol., 37, 316-323.

Kempler (G. M.) and Mc KaY (L. L.) (1979 b). - Genetic Evidence for Plasmidlinked Lactose Metabolism in Streptococcus lactis subsp. diacetylactis. Appl. Environ. Microbiol., 37, 1041-1043.

Kempler (G. M.) and Mc Kay (L. L.) (1981). - Biochemistry and Genetics of Citrate Utilization in Streptococcus lactis ssp. diacetylactis. J. Dairy Sci., 64, $1527-1539$.

Klaenhammer (T. L.), Mc Kay (L. L.) and Baldwin (K. A.) (1978). - Improved lysis of group N Streptococci for Isolation and Rapid Characterization of Plasmid Deoxyribonucleic Acid. Appl. Environ. Microbiol, 35 (3), 592-600.

Meyers (J. A.), Sanchez (D.), Elwell (L. P.) and Falkow (S.) (1976). - Simple Agarose Gel Electrophoretic Method for the Identification and Characterization of Plasmid Deoxyribonucleic Acid. J. Bacteriol., 127 (3), 1529-1537.

Pechmann (H.) and Teuber (M.) (1980). - Plasmid Pattern of Group N (lactic) Streptococci. Zbl. Bakt. Hyg. I. Abt. Orig. Cl, 133-136.

Terzaghi (B. E.) and Sandine (W. E.) (1975). - Improved Medium for lactic Streptococci and Their Bacteriophages. Appl. Microbiol., 29, 807-813.

WaLSH (P. M.) and Mc KAY (L. L.) (1981). - Recombinant Plasmid Associated with Cell Aggregation and High-Frequency Conjugation of Streptococcus lactis ML3. J. Bacteriol., 146 (3), 937-944.

Willshaw (G. A.), SMith (H. R.) and Anderson (E. S.) (1979). - Application of Agarose Gel Electrophoresis to the Characterization of Plasmid DNA in Drug-resistant Enterobacteria. J. Gen. Microbiol., 114, 15-25. 